\title{
ESTÁGIO SUPERVISIONADO UMA VISITA À REFLEXÃO CRÍTICA DA PRÁTICA DOCENTE
}

\author{
Robson B. Sampaio ${ }^{1}$
}

O presente artigo foi trabalho apresentado na finalização da disciplina EP911 - Estágio Supervisionado Anos Iniciais do Ensino Fundamental II na Faculdade de Educação - Unicamp, no segundo semestre de 2015, sob a orientação da professora Adriana Varani, que teve como objetivo viver e reconhecer o trabalho pedagógico realizado pela escola e em especial pela turma específica em que ocorreu o estágio e também elaborar e implementar um projeto de atuação em parceria com a professora. Esta proposta de estágio também acabou por ressaltar a importância da construção conjunta de saberes, em que o aluno estagiário e os educadores da escola se "comunicam" a respeito do "objeto cognoscível", comunicam-se a respeito da criança, refletem juntos sobre os determinantes da realidade que os circunda, elaboram em conjunto conhecimentos, e atuam sobre as circunstâncias com objetivo de transformá-las (FREIRE, 2000; FREIRE e OLIVEIRA, 2002). O estágio ocorreu no $1^{\circ}$ ano de uma escola Municipal de Ensino Fundamental quefica situada numa periferia da cidade de Campinas (na região Norte), sendo constituída por projetos de casa populares (CDHU e Minha Casa Minha Vida) e a população, em sua maioria, são de origem nordestina, negros e pardos.

A escola, de ensino regular, é de grande porte, com 12 (doze) salas, funciona em três turnos (da $1^{\circ}$ a $5^{\circ}$ ano no período da manhã, da $6^{\circ}$ a $9^{\circ}$ ano à tarde e a noite Educação de Jovens e Adultos (EJA) e alfabetização de adultos ligado à Fundação Municipal para Educação Comunitária (FUMEC). Ela recebe alguns alunos/as de inclusão. Segundo IDEB de 2013 (único que tivemos acesso), a escola se encontrava em "risco", pois a meta alcançada foi muito abaixo do esperando - 3, 1, quando o esperado era de " 4,3 ".

O estágio realizado produziu e vem produzindo em mim uma inflexão profunda do meu papel político e pedagógico, como sujeito de responsabilidade histórico e social de alteridade. Penso que há uma ordem social vigente que coisifica as relações sociais, indignificando o homem, que amplifica os atos de barbáries e naturaliza a violência (tanto do Estado como das civilizações). Acredito, entretanto, que há um movimento necessário, de outra possibilidade de socialização do homem, baseado numa desconstrução do todo e do tempo, no tempo da vida pautada pelo capitalismo, como uma única subjetividade e objetividade do ser concreto.

O estágio deu-me oportunidade de aprofundar em pensamento e em práticas cotidianas as contradições que vivemos na educação, através das noites investidas em estudos e debates coletivos, na sala de aula e, fora dela, dentro das lutas sociais do cotidiano da escola estagiada. O estágio também me fez pensar na postura do agir ético (KRAMER, 2013) docente, na responsabilidade de que temos ao ir a campo para experienciarmos o trabalho de professor e tentarmos extrair do contexto escolar as reflexões importantes e pertinentes para nossa formação, profissional e humana. Sabendo que a nossa formação neste processo acaba construindo marcas e deformações (ARROYO, 1999), na observação e participação no estágio na educação básica, dentro do contexto sociocultural e histórico das crianças, e do seu capital cultural (BOURDIEU, 2001).

Neste processo, senti-me atravessado por tudo isso, no acompanhamento do estágio para entender e desconstruir os preconceitos existentes. Não sei se consegui superar todos existentes em mim, mas já é um começo em pensar que existe e tenho que aprofundar mais. Estas reflexões fazem muito sentido para mim e para minha futura prática docente, mesmo que já faça educação para além das formalidades da profissão de ser professor.

\footnotetext{
${ }^{1}$ Universidade Estadual de Campinas.
} 
No movimento do cotidiano de vivenciar a prática do estágio, pude perceber que não é apenas praticismo escolar, do ensinar de forma mecânica e tentar colocar no tempo o currículo e as diretrizes municipais e nacional na educação básica, mas a construção deste cotidiano para/com as crianças e o fazer elas perceberem a própria potência nos seus aprendizados, ressignificação e empoderamento do próprio contexto social, sendo crianças na faixa etária dos 6 e 7 anos. Esta potência está materializada num trabalho que é construído coletivamente entre os atores envolvidos - crianças, professores, equipe de gestão, numa metodologia em que as culturas são consideradas e que vão passando por processo de apropriação e ressignificação.

A validade das teorias de Soares $(2004 ; 2008 ; 2010)$, Smolka (SMOLKA; LAPLANE, 1993) no processo de aprendizagem e apropriação alfabética das/pelas crianças, são potencializados pelo que elas já sabem e não por que elas vão saber ainda, mesmo que tenhamos identificado quatro casos mais emblemáticos no aprendizado. E estes não foram colocados à parte ou excluídos do processo coletivo, assim como foi meu contexto educacional. Remeto-me a minha experiência por ser o contrário no processo vivido por estas crianças com a professora, pois sou fruto de uma escola que não acreditou na potência da criança e intensificou os processos de exclusão, a despeito de hoje estar na Universidade. O cuidar e o querer educar é presente, é real, por essa professora e outras que pude ter a honra de conhecer nesta escola, pois demonstram uma crença no papel da educação como processo de apropriação dos bens culturais construídos pela humanidade, para a emancipação e criticidade do mundo e sua transformação, como práxis (FREIRE, 2000; FREIRE e OLIVEIRA, 2002) da busca de uma nova humanização necessária e urgente, que não esteja pauto pela relação de expropriação.

No decorrer da experiência de estágio, pude cooperar com a professora. Na maior parte das vezes mais aprendi que ajudei. Essa relação de estágio de implicação no trabalho pedagógico é fundamental para nossa formação responsável com outro, dentro de sua dimensão sociocultural e política, como ação de alteridade. Em muitos momentos me emocionei em sala, senti tristezas e raivas, por todo contexto de abandono que algumas crianças vivem no seu cotidiano. Mesmo assim, a doçura delas me baliza e orienta para o meu papel social. Os conflitos vividos são inerentes a nós seres humanos, que amamos e odiamos ao mesmo tempo, como parte da nossa humanidade e transformação dela, tudo isso são imprescindível como marcas fundamentais a formação da docência (ARROYO, 1987).

Outra dimensão, que tentei auscultar como prática de alteridade foram os olhares e sentimentos daquelas crianças, que são sujeitas da sua própria materialidade histórica, e não tábua rasa, esperando passivamente serem preenchidas de cultura (FREIRE, 2000; FREIRE e OLIVEIRA, 2002). Tive o maior sentimento de esperança e de acreditar que sou capaz de compor um mundo de significado com elas. Na educação, em especial na pedagogia me reencontrei como sujeito potente e capaz de mudar o mundo, porque esse mundo está dentro de mim, dos vários eus que estou querendo romper, com todos os paradigmas escritos pela sociedade, em forma de estigma social, que aqui não é seu lugar e nem deles, das crianças que vivenciam a violência diária, pelo abandono e invisibilidade.

Cada momento de conquista da criançada era meu também. Quando elas superam cada momento da alfabetização, das chamadas etapas: pré-silábica, silábica e alfabeta (SOARES, 2004; 2008; 2010), de cada morfema e fonema apropriado, dos olhos brilhantes delas em cada letra, juntado em pedacinho e a pedacinho de sentido daquela decodificação gráfica, e (re)codificado, eram momentos de conquista para mim também as vozes baixas e trêmulas nas rodas de leituras, ou na "Biblioteca Asas de Papel", foram e são momentos surpreendentes para mim e para a professora regente. Assim também como percebi que era para a professora que irá acompanhá-los no $2^{\circ}$ ano, como processo de implementação da ideia de ciclo de conhecimento e humanização, no qual elas vêm apreendendo, pesquisando, dialogando em grupos de estudos na escola. 
Analisando tudo isso, remeto-me à minha experiência de ter vivenciado o contrário deste processo rico vivenciado por essas crianças com a professora e na escola, pois sou fruto de uma escola (como a própria política pública educacional da época) que não acreditou na potência das crianças e acabou intensificando os processos de exclusão educacional de muitas crianças da minha época, que não almejaram a continuidade em sua formação por acharem que o seu espaço não fosse uma escola crítica e problematizadora dos valores societário, para além de fornecedora de mão de obra para o Mercado.

A despeito disto, vejo uma maior atuação da Faculdade de Educação da Unicamp, problematizar nosso estágio, o nosso papel político e social, como agentes éticos na construção coletiva das crianças, das escolas, das políticas, para uma transformação integral do seres humanos, dentro de uma criticidade social dos valores e das nossas ações no cotidiano societário.

Para que possamos avançar no sentido de uma educação pública comprometida com estágio do desenvolvimento da sociedade, com perspectiva emancipatória, em busca do reino da felicidade e justiça social, precisamos consolidar uma escola mais democrática e participativa. Acredito que o papel do educador e da escola, tanto na gestão e no desenvolvimento cognitivo e intelectual são de extremas importâncias como prática formativa, contribuindo para o diálogo, dialógico e dialético de todos sujeitos atuantes na escola, que o

ensinar não é transferir conhecimentos, conteúdos, nem formar, é ação pela qual um sujeito criador dá forma, alma a um corpo indeciso e acomodado. Não há docência sem discência, as duas se explicam e seus sujeitos, apesar das diferenças, não se reduzem à condição de objeto, um do outro. Quem ensina aprende ao ensinar e quem aprende ensina ao aprender. (FREIRE, 2000, p. 11)

\section{Referências}

ARROYO, M. G. Ciclos de Desenvolvimento Humano e Formação de Educadores. Educação e Sociedade, Campinas, n. 68, p. 143-162, 1999.

O estágio supervisionado como alternativa à melhoria do ensino. mimeo, 1987.

BOURDIEU, P. A economia das trocas simbólicas. 5. ed. São Paulo, SP: Perspectiva, 2001.

FREIRE, P. Pedagogia da Autonomia: saberes necessários à prática educativa. 16. ed. São Paulo: Paz e Terra, 2000 (Coleção Leitura).

; OLIVEIRA, R. D. Extensão ou comunicação? 12. ed. Rio de Janeiro, RJ: Paz e Terra, 2002.

KRAMER, S. A Educação Como Resposta Responsável: apontamentos sobre o outro como prioridade. In: FREITAS, M. T. (Org.) Educação, Arte e Vida em Bakhtin. Belo Horizonte: Autêntica, 2013. p. 29-46.

QEDU, E. L. L. S.: Ideb 2013. Disponível em: <http://www.qedu.org.br/escola/187443-emefedson-luis-lima-souto/ideb> Acesso em: 06 jul. 2015.

SMOLKA, A. L. B.; LAPLANE, A. O trabalho em sala de aula: Teorias para quê? Caderno ESE, FE/UFF, n. 1, nov/1993. (Alfabetização e Leitura). 
SOARES, M. Letramento e escolarização. In: RIBEIRO, V. M. Letramento no Brasil, reflexões a partir do INAF 2001 (Org.). 2. ed. São Paulo: Global, 2004.

Alfabetização e Letramento. 5. ed. São Paulo: Contexto, 2008.

Letramento: um tema em três gêneros. 4. ed. Belo Horizonte: Autêntica Editora, 2010.

\section{Sobre o autor}

Robson B. Sampaio é graduando em Pedagogia na Faculdade de Educação da Unicamp, membro do grupo de pesquisa Educação Aberta/NIED-Unicamp e bolsista do PIBIC/CNPq/SAE/NIED-Unicamp. É tabém membro do coletivo Revoada de Cultura Digital e militante do Software Livre e Cultura Digital em Campinas.

E-mail: reductio.ad.ethos@gmail.com. 